\title{
IDENTITAS VISUAL DAN MEDIA PROMOSI WISATA EDUKASI JENDELA ALAM
}

\author{
Sari Ramadeni ${ }^{1}$, Didit Widiatmoko Soewardikoen ${ }^{2}$ \\ ${ }^{1,2}$ Universitas Telkom
}

\begin{abstract}
Abstrak : Indonesia memiliki potensi keindahan dan kekayaan alam yang sangat besar, dimana potensi tersebut dapat dirangkai menjadi satu daya tarik wisata. Salah satu objek wisata yang memaksimalkan potensi alam Indonesia adalah wisata Jendela Alam yang terletak di daerah Lembang, kabupaten Bandung Barat. Namun tempat wisata ini masih belum dikenal oleh masyarakat luas karena promosi yang dilakukan belum maksimal, sehingga kurangnya minat masyarakat untuk berkunjung ke wisata edukasi alam. Metode yang digunakan dalam pengumpulan data adalah observasi dan dokumentasi, wawancara, kuesioner, dan studi pustaka. Perolehan data dianalisis menggunakan matriks perbandingan. Perancangan ulang identitas visual diperlukan untuk menciptakan sebuah image yang mudah dikenal oleh wisatawan, dan penerapan pada media promosi yang sesuai. Perancangan difokuskan pada unsur pariwisata edukasi alam dan sebagai acuan dalam visualisasi media-media promosi. Adanya perancangan ini akan membantu pihak Jendela Alam membuat identitas visual dan media promosi untuk meningkatkan minat masyarakat agar tertarik berkunjung ke wisata edukasi alam.
\end{abstract}

Kata Kunci : jendela alam, wisata edukasi alam, identitas visual, media promosi

\begin{abstract}
Indonesia has the potential beauty and great natural wealth, where could be turned into a tourist attraction. One of the destinations that could maximize the potential of Indonesia's educational tour of nature is a Jendela Alam which located in Lembang, West Java. But these places are still not well known by the public, because the promotion is not maximized, so that people are less interested in visiting this educational tour of nature. The methods used in data collection are observation and documentation, interviews, questionnaires, and literature. Data were analyzed using matrix data comparison. The result, redesigning the visual identity needed to create an image that is easily recognized by tourists, and the application to the appropriate media campaign. The design is focused on nature tourism and educational element as a reference in the visualization of media promotion. The existence of this design will help Jendela Alam publishes travel visual identity and media promotions to increase public to be more interested in visiting educational tour of nature.
\end{abstract}

Keywords: jendela alam, educational tours of nature, visual identity, promotional media

Penulis adalah mahasiswa dan staf pengajar Program Studi Desain Komunikasi Visual, Fakultas Industri Kreatif - Universitas Telkom, email: sramadenii@gmail.com 


\section{PENDAHULUAN}

Indonesia dengan kekayaan dan keanekaragaman hayati baik di darat maupun di laut memiliki peluang yang sangat besar dalam meraih manfaat dari alam, salah satu manfaat yang dapat diperoleh adalah dengan cara pengembangan daerah yang subur untuk dijadikan sebagai objek wisata alam. Dasar hukum pengembangan pariwisata alam yang sesuai dengan prinsip kelestarian adalah UU No 9 tahun 1990 tentang kepariwisataan, undang-undang tersebut menyebutkan bahwa dalam rangka pengembangan dan peningkatan kepariwisataan, diperlukan langkah-langkah pengaturan yang semakin mampu mewujudkan keterpaduan dalam kegiatan penyelenggaraan kepariwisataan, serta memelihara kelestarian dan mendorong upaya peningkatan mutu lingkungan hidup serta objek dan daya tarik wisata.

Kawasan Bandung memiliki banyak tempat wisata yang sudah dikenal oleh wisatawan lokal maupun mancanegara. Seiring dengan perkembangan jaman dan meningkatnya jumlah penduduk di Bandung, tentunya semakin tinggi juga potensi objek wisata yang menarik untuk dikunjungi. Agar dapat bersaing, perlu adanya faktor pembeda antar objek wisata, salah satunya adalah objek wisata yang menawarkan edukasi menyenangkan terhadap para pengunjung. Sebelum berwisata, masyarakat akan mempertimbangkan beberapa kriteria destinasi wisata yang akan mereka kunjungi, salah satu kriterianya adalah objek wisata yang cocok untuk liburan keluarga. Kriteria ini mencakup pengunjung lansia, dewasa, dan anak-anak.

Dalam kesempatan ini, penelitian akan ditujukan kepada wisata "Jendela Alam". Tempat wisata ini berlokasi di Lembang, Bandung Jawa Barat. Jendela Alam merupakan tempat wisata yang menawarkan area belajar, tempat outbound, dan rekreasi untuk anak-anak dan dewasa dengan sentuhan alam yang indah serta udara yang sejuk, cocok pula sebagai tempat wisata keluarga 
untuk mengenal alam. Wisata edukasi yang diterapkan di Jendela Alam tidak hanya cocok untuk anak-anak, namun juga bermanfaat untuk orang dewasa maupun lansia. Karena pada dasarnya melatih sikap orang dewasa jauh lebih sulit dibandingkan anak-anak. Contoh hal kecil ketika orang dewasa sudah terbiasa membuang sampah sembarangan, maka kebiasaan tersebut akan sulit diubah jika tanpa solusi yang inovatif. Peran Jendela Alam disini adalah untuk mengubah kebiasaan buruk seperti itu menjadi sebuah kegiatan yang positif, misalnya dengan cara mendaur ulang sampah organik atau membuat kebun kecil konvensional yang dapat diterapkan dirumah. Kegiatan tersebut akan terasa manfaatnya kelak untuk mengisi waktu luang di masa tua. Anak-anak akan dikenalkan dengan berbagai kegiatan pertanian dan peternakan. Sementara untuk kategori dewasa ada pilihan untuk belajar tentang daur ulang air hujan dan air limbah melalui cara-cara penjernihan air dan lain sebagainya. Jendela Alam Sebagai pusat area belajar, juga menyediakan program edukasi untuk sekolah, kegiatan live in dan kegiatan sekolah lainnya mulai dari Play Group sampai dengan Tingkatan SMA, perorangan/individu, instansi, dan program workshop praktek yang diberikan untuk masyarakat usia paruh baya sampai dengan pensiunan.

Pada awalnya Jendela Alam memiliki kendala operasional, saat itu permintaan pengunjung tidak selalu dapat dipenuhi karena kondisi kebun belum masuk masa panen, begitu pun dengan peternakannya. Oleh karena itu, pihak Jendela Alam membuat timeline panen bulanan sehingga kunjungan dapat disesuaikan dengan habitat yang sedang dalam masa panen saja. Khusus untuk pengunjung rombongan disarankan agar memesan minimal 1 bulan sebelumnya untuk memastikan kondisi habitat wisata Jendela Alam.

Selain kendala operasional, adalah kegiatan promosi yang sudah dilakukan Jendela Alam selama ini. Promosi kesekolah-sekolah hanya menggunakan media 
brosur dan materi presentasi. Kedua media ini dirasa kurang efektif untuk menarik minat pengunjung. Di kawasan lokasi wisatanya sendiri, Jendela Alam tidak memasang media promosi kecuali di dalam komplek Graha Puspa. Dari hasil wawancara, dapatkan disimpulkan bahwa wisata Jendela Alam berfokus pada bisnis kepariwisataan dan perkebunan konvensional. Hingga saat ini, kegiatan promosi Jendela Alam hanya kesekolah-sekolah yang didukung oleh media brosur dan materi presentasi saja. Selain itu, Jendela Alam juga jarang memasang iklan. Menurut hasil observasi pada hari yang sama pada bulan Februari 2016, pengunjung wisata artifisial atau wisata buatan lebih banyak daripada pengunjung wisata Jendela Alam. Didukung dengan hasil wawancara kepada pengunjung Jendela Alam, diketahui bahwa identitas visual dan media promosi objek wisata ini kurang menarik jika dibandingkan dengan wisata artifisial. Selain itu, grafik kunjungan pertahunnya juga tidak stabil, Jendela Alam hanya ramai dikunjungi pada musim-musim liburan sekolah. Untuk mengatasi hal ini, Jendela Alam perlu merancang ulang identitas visual dan media promosi yang sesuai dengan target konsumen Jendela Alam. Hasil perancangan ini akan meningkatkan minat masyarakat agar tertarik berkunjung ke wisata alam berbasis edukasi dan juga sekaligus menstabilkan jumlah pengunjung setiap bulannya dalam setahun.

\section{KAJIAN TEORI}

Dalam buku Building Brand Identity (Upshaw, 1995 : 12) menjelaskan bahwa brand identity atau identitas merek merupakan konfigurasi kata-kata, gambar, ide-ide, dan asosiasi yang berasal dari sebuah persepsi konsumen terhadap merek dagang. Adapun visual yang mendukung brand identity tersebut diataranya adalah logo, stationery set, co-card, merchandise, dan maskot. Salah Wahab dalam bukunya Manajemen Kepariwisataan (Wahab, 2003 : 150-151), 
menjelaskan tentang ciri khas promosi pariwisata yaitu promosi beranjak dari produksi dan berkaitan dengan upaya memacu kemungkinan penjualannya, biasanya dilakukan dengan perantaraan media seperti iklan, publisitas, dan hubungan masyarakat, meliputi seluruh kegiatan penyebaran informasi (periklanan, film, brosur, buku panduan, poster, dan sebagainya), dan dilakukan melalui beragam saluran media massa (surat kabar, bioskop, radio, TV, pengiriman surat, dan lain-lain) kepada wisatawan real atau yang masih potensial. Ada banyak alasan melakukan suatu promosi, misalnya ingin menjual produk baru, penurunan penjualan, banyaknya kompetitor, memperbaiki citra produk, pembentukan positioning baru di benak konsumen, dan lain sebagainya. Tujuan promosi akan berpengaruh pada aspek-aspek lainnya, seperti konsep promosi, media yang digunakan, target audiens, dan pada akhirnya biaya yang akan dikeluarkan untuk promosi tersebut (Ardhi, 2007 : 78).

Menurut Amborse dan Harris, (Amborse \& Harris, 2005 dalamAnggraini dan Natalia, 2014 : 74-77) menjelaskan bahwa layout adalah penyusunan dari elemen-elemen desain yang berhubungan ke dalam sebuah sebuah bidang sehingga membentuk susunan artistik. Hal ini bisa juga disebut manajemen bentuk dan bidang. Dalam sebuah layout, terdapat beberapa elemen seperti elemen teks, elemen visual, dan elemen lainnya. Tujuan utama layout adalah menampilkan elemen gambar dan teks agar menjadi komunikatif dan dapat memudahkan pembaca menerima informasi yang disajikan.Model AISAS pada dasarnya merupakan pengembangan dari model hierarki efek sebelumnya (khususnya AIDA), dengan menambahkan atau memodifikasi beberapa elemen. Elemen yang ditambahkan oleh model ini adalah aktivitas pembelajaran oleh khalayak (pencarian informasi) dan aktivitas berbagi informasi dengan konsumen lain. (Wenats dkk., 2012:69-71) 


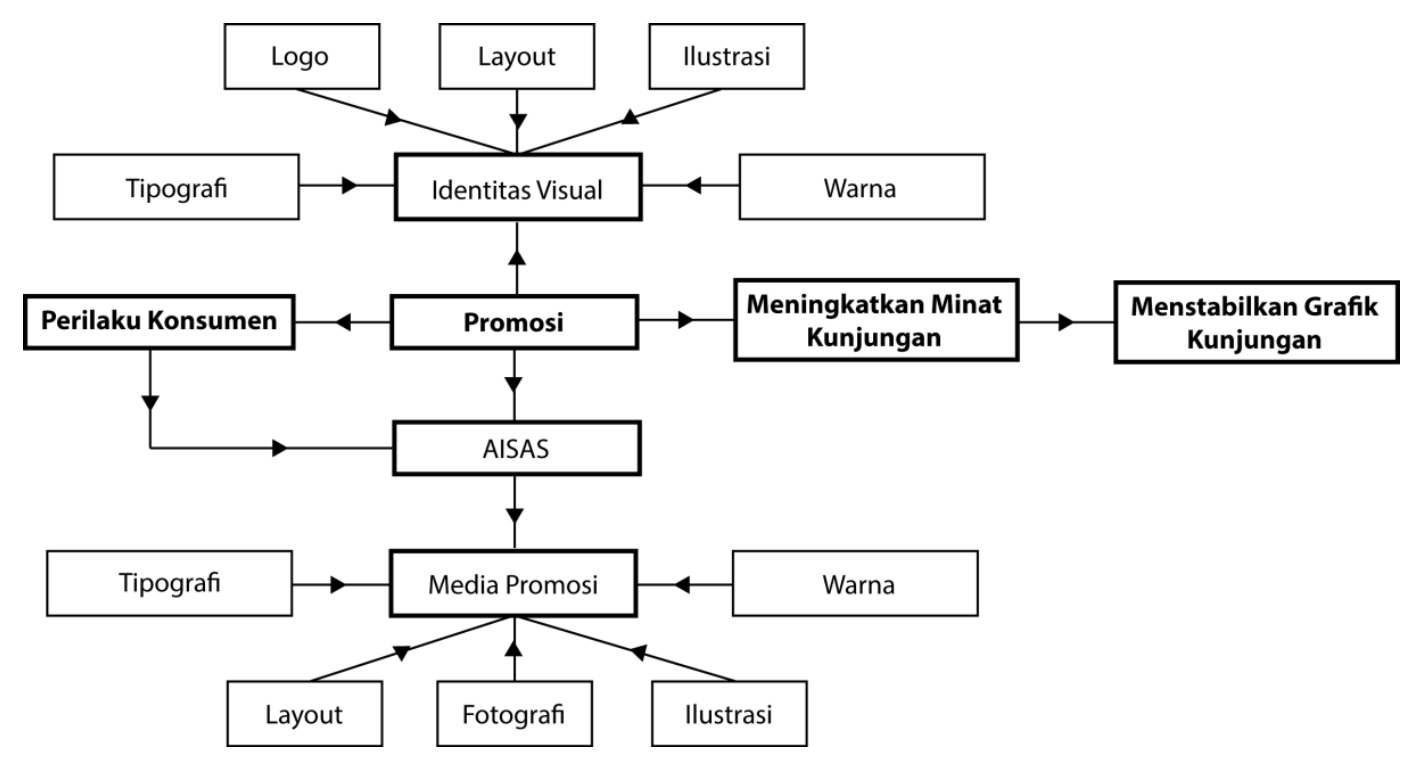

Gambar 1. Kerangka teoretik

Sumber, Ramadeni $2016: 35$

\section{METODE PENELITIAN}

Dalam perancangan kali ini, dilakukan observasi pada objek penelitian yang bersangkutan yaitu Jendela Alam di Kabupaten Bandung Barat. Observasi ini mencakup objek lokasi penelitian, objek lokasi pesaing, kegiatan pengunjung, serta proses edukasi yang dilakukan. Kegiatan tersebut didukung dengan teknik dokumentasi yang dilakukan langsung selama proses observasi untuk memperoleh data informasi terdahulu dari pihak perusahaan. Data internal didapatkan melalui wawancara tidak terstruktur terhadap Komisaris dan Manajer Pemasaran Jendela Alam. Selain itu, kuesioner disebarkan secara random kepada 100 responden untuk mengetahui tanggapan pengunjung dan tingkat ketertarikan masyarakat terhadap objek wisata Jendela Alam.

Adapun studi pustaka dilakukan melalui berbagai sumber buku, jurnal, artikel, dan internet yang berkaitan dengan sejarah perusahaan, identitas visual objek wisata, promosi kepariwisataan, serta teori lainnya yang berkaitan dengan 
Desain Komunikasi Visual. Untuk mempermudah proses penelitian, maka dibuat matriks perbandingan terhadap potensi dan media promosi pesaing. Dalam hal ini, pesaing yang dijadikan objek perbandingan adalah Little Farmers, Alam Wisata Cimahi, dan Kampung Gajah Wonderland.

\section{HASIL DAN DISKUSI}

Wisata Jendela Alam termasuk ke dalam jenis wisata alam yang telah dibudidayakan dengan mengandalkan penggunaan tanah di suatu lahan untuk mengembangkan sebuah agrowisata. Jendela Alam memiliki area kebun pertanian konvensional seluas $\pm 1,6$ hektar. Vegetasi yang dibudidayakan wisata Jendela Alam dikelompokkan dalam 3 bidang, yaitu : a) Kebun sayuran dan palawijaya, antara lain : brokoli, kangkung, tomat, wortel, buncis, kapri, jagung, labu raksasa dan pisang. b) Tanaman obat berkhasiat : rosemary, temu-temuan, brotowali, dan pagoda. c) Kebun stroberi.Selain itu, ada juga beberapa jenis hewan ternak seperti kambing etawa, kambing kacang, macam-macam ras kelinci dan ayam, ayam kampung Arab, kuda poni, burung puyuh, rusa, sapi, bebek, dan angsa. Dengan konsep kebun pertanian terpadu/integrated farming, Jendela Alam sedang mengupayakan pengolahan limbah organik baik dari ternak maupun kebun. Jendela Alam menawarkan berbagai macam jenis kegiatan edukasi melalui koleksi habitatnya, diataranya adalah edukasi peternakan, perkebunan, fun games, workshop, outbound dan berenang. Dikarenakan Jendela Alam tidak selalu mengalami masa panen, maka faktor kondisi alam pun menjadi salah satu pertimbangan apakah kegiatan edukasi dapat dilakukan atau tidak. Oleh karena itu, kegiatan yang ditawarkan bersifat fleksibel dan dapat di atur sesuai kebutuhan konsumen.

Wisata Jendela Alam ramai pengunjung pada hari libur. Pengunjung berasal dari berbagai daerah, hal ini terlihat dari banyaknya kendaraan pribadi yang terdapat di area parkir. Ada beberapa bus rombongan yang terlihat di area parkir 
wisata Jendela Alam, dilihat dari nomor polisi lebih banyak berasal dari luar Kota Bandung. Rombongan bus ini mayoritas merupakan kunjungan yang diadakan oleh sekolah-sekolah umum dan madrasah. pengamatan juga dilakukan pada media promosi yang berada di sekitar kawasan wisata Jendela Alam. Media promosi yang terlihat diantaranya adalah billboard dan signage Jendela Alam yang diletakkan di depan gerbang komplek Graha Puspa, namun billboard dan signage tersebut berukuran kecil. selain itu terdapat spanduk dan $x$-banneryang diletakkan di area parkir.

Berdasarkan hasil analisis data wawancara, kuesioner, dan matriks perbandingan terhadap ketiga objek pesaing, diketahui bahwa logo Jendela Alam belum memiliki citra diri yang baik, unsur visualnya tidak mudah diingat karena desainnya terlalu rumit. Selain itu konsumen sekarang lebih suka mencari segala sesuatu yang bisa menyentuh sisi personal mereka. Jika produk wisata mendominasi konsumen anak-anak, maka sebaiknya menggunakan unsur yang berhubungan dengan karakter anak-anak yang unik dan ceria. Selain identitas, media promosi yang telah dibuat oleh Jendela Alam tidak ada kesenadaan elemen desain di setiap medianya. Sekarang masyarakat lebih cenderung mengakses segala informasi melalui internet, sehingga metode marketing yang telah Jendela Alam lakukan sebelumnya yaitu melalui presentasi ke sekolahsekolah harus dilengkapi dengan media internet.

\section{Konsep Perancangan}

Konsep Pesan. Pesan yang dikomunikasikan dalam perancangan ini adalah "konsep wisata yang menyenangkan dengan mengenal lebih dekat manfaat dan fungsi potensial alam yang ada disekitarnya". Tagline yang direkomendasikan adalah "Experience Comes by Nature". Penggunaan tagline tersebut didasari oleh penyesuaian terhadap karakter dari wisata Jendela Alam. "Experience Comes by Nature" memiliki makna pengalaman datang dari alam, dengan tagline tersebut 
diharapkan wisata Jendela Alam dapat menjadi tempat yang memberikan pengalaman menarik untuk keluarga melalui edukasi alam.

Tagline merupakan bagian yang penting untuk memperkuat positioning di masyarakat. Tagline yang digunakan oleh wisata Jendela Alam saat ini adalah "Save Nature For The Future". Peubahan tagline diperlukan guna memperjelas fokus bisnis yang dijalankan. Tagline yang direkomendasikan adalah "Experience Comes by Nature". Penggunaan tagline tersebut didasari oleh penyesuaian terhadap karakter wisata Jendela Alam. "Experience Comes by Nature" bermakna pengalaman datang dari alam, dengan tagline ini diharapkan wisata Jendela Alam dapat menjadi tempat yang memberikan pengalaman menarik untuk keluarga.

Konsep Kreatif. Perancangan Tugas Akhir ini menggunakan pendekatan melalui tagline yang telah dibentuk yaitu "Experience Comes by Nature". Ide kreatif yang muncul dari pendekatan tersebut adalah dengan menjadikan para pengunjung sebagai "petani sehari". Sebutan ini seolah mengajak para pengunjung beralih peran menyelami kehidupan sebagai seorang petani. Pengunjung diharapkan mengerti bagaimana cara berinteraksi dengan alam, dimana pengalaman ini tidak akan mudah didapatkan di kota-kota besar. Untuk dapat menyampaikan ide "petani sehari" tersebut, dibuatlah media pengantar berupa maskot sebagai daya tarik pengunjung. Karakter yang akan dijadikan sebagai maskot adalah kelinci yang diadaptasi dari logo wisata Jendela Alam. Kelinci ini akan divisualisasikan menggunakan kostum layaknya seorang petani.

Maskot. Karakter yang dijadikan maskot adalah kelinci yang diadaptasi dari logo wisata Jendela Alam. Kelinci ini akan divisualisasikan menggunakan kostum layaknya seorang petani. Meksipun kelinci merupakan makhluk yang kecil, terlihat rapuh dan terkesan lemah, namun hewan lucu ini merupakan makhluk yang sangat lincah. Filosofi ini berhubungan dengan pengunjung Jendela Alam yang mayoritas anak-anak. Meskipun usianya masih tergolong sangat muda, 
mereka harus lincah, aktif, dan semangat untuk terus belajar tanpa mengenal rasa takut.

Konsep Visual. Dalam menarik wisatawan melalui identitas visual wisata Jendela Alam, langkah pertama yang dilakukan adalah mengembangkan elemen pendukung logo yang mampu merepresentasikan visi, misi, filosofi perusahaan dan servis bisnis. Elemen-elemen pendukung ini kemudian diterapkan secara konsisten dan terintegritas secara menyeluruh ke dalam media-media promosi yang ada agar tercipta brand awareness yang diharapkan. Dalam perancangan elemen pendukung logo digunakan beberapa unsur visual yang dapat mempengaruhi gaya gambar dan warna, yaitu fotografi human interest dan unsur alam.

Fotografi Human Interest, Teknik fotografi inimerupakan sebuah potret yang diambil untuk merekam emosi, perasaan, maupun aktivitas seseorang. Teknik ini digunakan dalam menampilkan kegiatan-kegiatan yang dilakukan pengunjung wisata Jendela Alam guna menarik simpati audiens yang melihat foto tersebut.

Nature, Wisata Jendela Alam melekat erat dengan unsur alamnya, tempat ini merupakan kombinasi wisata alam dan wisata edukasi. Sesuai dengan namanya, di tempat wisata ini terdapat berbagai macam unsur alam seperti tanaman, pepohonan, hewan, pemandangan alam termasuk matahari dan juga awan. Unsur-unsur tersebut dijadikan elemen visual dengan landasan sebagai penggambaran suasana alam.

Identitas Visual. Penggayaan Desain, identitas visual lebih banyak menggunakan unsur alam, selain diambil dari nama Jendela Alam juga dikarenakan objek wisata tersebut mengusung konsep wisata alam. Perancangan identitas visual mengambil dari bentuk jendela sesuai dengan nama Jendela Alam, bentuk kelinci sebagai salah satu binatang yang disayangi anak-anak, dan 
bentuk matahari sebagai bagian dari unsur alam. Perbandingan ukuran logogram dan logotype disesuaikan secara fleksibel sesuai dengan media yang digunakan. Tipografi pada logo menggunakan perpaduan fontCarter One yang dimodifikasi. Hal ini dimaksudkan untuk meningkatkan keterbacaan logo. Salah satu yang dilakukan dalam perancangan ulang identitas visual Jendela Alam adalah melakukan perubahan pada beberapa warna yang kurang menarik.
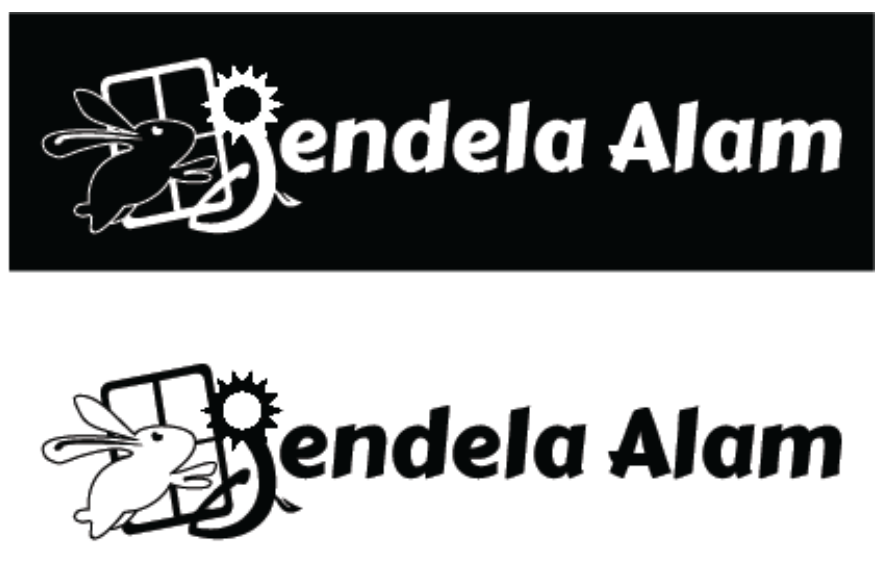

Gambar 1. Hasil penyederhanaan Logo Jendela Alam Sumber : Dokumentasi Pribadi

Konsep Media. Kegiatan promosi akan dilaksanakan dalam kurun waktu 1 tahun. Berikut pemilihan media berdasarkan tahap tujuan komunikasi menggunakan konsep AISAS :

Tabel 1. Tahapan Promosi dengan model AISAS

Sumber:Dokumentasi Pribadi

\begin{tabular}{|c|c|c|c|}
\hline Tujuan Komunikasi & Strategi & Media & Lokasi \\
\hline Informing & $\begin{array}{c}\mathrm{A} \\
\text { (Attention) }\end{array}$ & $\begin{array}{l}\text { a. Corporate Identity : Logo, tiket, } \\
\text { kartu namadan email marketing, } \\
\text { maskot, co-card, seragam fasilitator, } \\
\text { papan nama, dan papan harga. }\end{array}$ & $\begin{array}{l}\text { Area objek } \\
\text { wisata } \\
\text { Jendela } \\
\text { Alam. }\end{array}$ \\
\hline Persuading & $\begin{array}{c}\mathrm{I} \\
\text { (Interest) } \\
\mathrm{S} \\
\text { (Search) }\end{array}$ & $\begin{array}{l}\text { a. Website dan media sosial, meliputi : } \\
\text { Facebook, Twitter, dan Instagram. } \\
\text { b. Iklan media cetak, seperti : leaflet, } \\
\text { poster, x-banner, spanduk, billboard, } \\
\text { dan umbul-umbul. }\end{array}$ & $\begin{array}{l}\text { Media online } \\
\text { dan tempat } \\
\text { umum. }\end{array}$ \\
\hline
\end{tabular}




\begin{tabular}{|c|c|c|c|c|}
\hline $\begin{array}{l}\text { Reminding } \\
\mathrm{R}\end{array}$ & $\begin{array}{c}\text { A } \\
\text { (Action) } \\
\text { S } \\
\text { (Share) }\end{array}$ & & $\begin{array}{l}\text { Merchandise : Alat tulis, topi, } t \text {-shirt, } \\
\text { dan stiker. } \\
\text { Family member card dan outfit } \\
\text { petani. }\end{array}$ & $\begin{array}{l}\text { Area objek } \\
\text { wisata } \\
\text { Jendela } \\
\text { Alam. }\end{array}$ \\
\hline
\end{tabular}

Rincian media promosi : 1) Kartu nama dan email marketing. Kartu nama sangat dibutuhkan dalam kegiatan berbisnis, karena fungsinya sebagai identitas perusahaan yang dapat menunjang kegiatan internal maupun eksternal. Kartu namamemudahkan penerimanya untuk memperoleh informasi mengenai pihak pengelola wisata. Konsep kartu nama untuk wisata Jendela Alam adalah dengan menampilkan visual logo, ilustrasi, alamat lengkap, kontak, website, dan akun media sosial. Sedangkan, email marketing adalah sebuah email dengan bentuk visual yang lebih menarik daripada hanya sekedar menampilkan tulisan seperti email pada umumnya. Email Marketing ini digunakan untuk menyebarkan pesan dan informasi secara luas kepada konsumen.

2) Merchandise. Salah satu media promosi yang bersifat pengingat terhadap wisata Jendela Alam. Beberapa jenis merchandise ada yang dibagikan secara cuma-cuma seperti stiker yang dipilih karena pengunjung Jendela Alam merupakan kalangan menengah hingga menengah atas yang mayoritas memiliki kendaraan pribadi, dan ada juga yang berbayar seperti alat tulis, topi, dan $t$-shirt. Kedua jenis merchandise tersebut akan digunakan untuk meningkatkan awareness terhadap wisata Jendela Alam. Keuntungan merchandise berbayar dapat dijadikan sebagai salah satu sumber pendapatan bagi perusahaan.

3) Family member card dan outfit petani. 4) Family member card adalah sebuah kartu member yang diberikan pada kunjungan pertama konsumen. Kartu ini berisikan nama anggota keluarga dan kolom cap dimana setiap pengumpulan 10 cap kunjungan akan mendapatkan bingkisan menarik dari Jendela Alam. Sedangkan, outfit petani terdiri dari apron, boots, dan topi caping untuk anak- 
anak. Diharapkan dengan outfit ini dapat menarik minat anak-anak untuk menjadi sosok petani sesungguhnya. Family member card dan outfit petani ini hanya bisa didapat oleh pengunjung tiket terusan.

5) Maskot. Digunakan sebagai karakter yang menggambarkan identitas wisata Jendela Alam. Kehadiran maskot biasanya menjadi daya tarik tersendiri bagi anak-anak untuk diajak berfoto maupun hanya sekedar saling berjabat tangan. Perancangan desain maskot dapat diterapkan dalam bentuk patung maupun kostum. 6) Seragam karyawan. Berfungsi sebagai identitas para karyawan wisata Jendela Alam. Selain agar terlihat rapi, seragam berupa rompi ini juga berfungsi untuk membedakan antara staff dan fasilitator. Seragam fasilitator dirancang khusus dengan warna yang mencolok agar mudah dikenali oleh pengunjung.

7) Leaflet. Penggunaan leaflet dimaksudkan untuk menyampaikan pesan atau informasi yang lebih banyak. Leaflet ditujukan kepada calon pengunjung untuk membujuk serta memberikan informasi secara detail mengenai paket wisata yang tersedia. 8) Flyer, poster, x-banner, spanduk, billboard, dan umbulumbul.Digunakan untuk memberikan informasi wisata yang lebih sedikit dibandingkan leaflet. Pada perancangan ini media-media tersebut dibagi menjadi dua tujuan yaitu untuk menginformasikan dan untuk membujuk target audiens. Media umbul-umbul dipilih karena jarak dari jalur utama jalan Setiabudi ke lokasi wisata Jendela Alam sekitar $3 \mathrm{~km}$., oleh karena itu perlu adanya media umbulumbul yang akan ditempatkan mulai dari belokan terminal Ledeng dan di jalan Sersan Bajuri.

9) Papan nama.Perancangan papan nama dengan tidak memasukkan konten terlalu banyak, hanya akan memuat nama tempat wisata, logo, dan alamat. Selain itu, perlu diperhatikan juga antara ukuran papan nama dengan jarak pandang audiens. 10) Tiket, Perancangan tiket bertujuan untuk 
menandakan bahwa pengunjung telah melakukanb transaksi di kasir Jendela Alam. Tiket dibagi menjadi 3 jenis, tiket satuan, tiket terusan, dan gelang karet yang dijadikan sebuah merchandise.

11) Website. Media online ini dipilih karena dapat menjangkau khalayak secara luas. Website resmi wisata Jendela Alam akan memuat segala informasi perusahaan, jenis kegiatan, harga, promo, event, hingga dokumentasi kegiatan. Halaman website ini nantinya akan terintegrasi dengan semua akun media sosial Jendela Alam. 12) Media sosial (Facebook, Twitter, Instagram, dan Line). Media sosial merupakan salah satu media promosi yang saat ini paling diminati banyak orang. Media ini berperan sebagai penghubung antara pihak pengelola wisata dengan masyarakat luas untuk kebutuhan penyampaian informasi dengan mudah dan cepat. Bentuk promosi yang dilakukan pada media ini adalah digital poster yang bersifat membujuk audiens agar tertarik berkunjung ke wisata Jendela Alam.

\section{Rancangan Karya Visual}

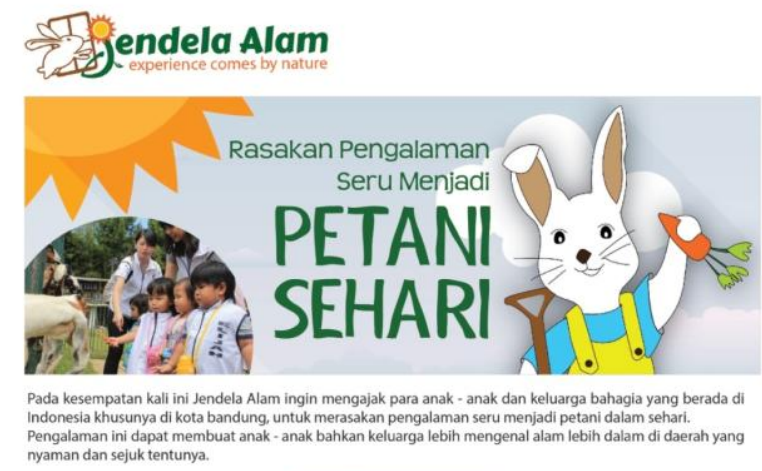

\section{INFO LEBIH LANJUT}

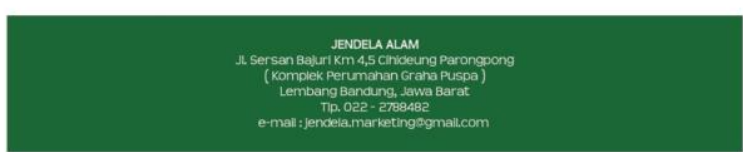

f $\mathrm{E}$ 回

Gambar 2. Rancangan Email Marketing Sumber : Dokumentasi Pribadi 


\section{KESIMPULAN}

Perancangan ulang identitas visual dan media promosi Jendela Alam untuk memperkuat brand awareness, sehingga dapat menarik minat masyarakat agar berkunjung ke wisata alam berbasis edukasi. Media promosi yang disesuaikan dengan perilaku konsumen dan penjadwalan media yang tepat dapat membantu menstabilkan jumlah pengunjung setiap bulannya dalam setahun, sehingga akan terjadi peningkatan pertumbuhan bisnis yang berarti. Untuk mendapatkan hasil yang lebih baik lagi, perancangan program promosi dan penjadwalan media dilakukan secara tersusun dan berkelanjutan. Tahap berikutnya adalah memperluas kerja sama dengan pihak-pihak yang berpotensi, seperti sekolah, komunitas pendidikan dan agen pariwisata.

\section{DAFTAR PUSTAKA}

Anggraini, L. \& Kirana, N., 2014. Desain Komunikasi Visual. Bandung: Nuansa Cendekia.

Ardhi, Y., 2013. Merancang Media Promosi Unik dan Menarik. Yogyakarta: TAKA Publisher.

Aritonang, L. R., 2007. Riset Pemasaran Teori \& Praktek. Bogor: Ghalia Indonesia.

Giwanda, G., 2002. Panduan Praktis Menciptakan Foto Menarik. Jakarta: Puspa Swara, Anggota Ikapi.

Kusrianto, A., 2007. Pengantar Desain Komunikasi Visual. Yogyakarta: CV. Andi Offset.

Munandar, U., 2009. Pengembangan Kreativitas Anak Berbakat. Jakarta: Rineka Cipta.

Nazir, M., 1998. Metode Penelitian. Rineka Cipta: Jakarta.

Purwanto, B.B., 2006. Desain Grafis. ATG Trisakti. 
Rizka, A. dan Soewardikoen, D. W., 2014. Brand Identity Design of The Bay Bali. Jurnal Komunikasi Visual Wimba. Volume 06(N0.2/2014). http://www.academia.edu/10214782/brand identity design of the bay bali

Rohidi, T. R. R., 2011. Metodologi Penelitian Seni. Cipta Prima Nusantara: Semarang.

Sangadji, E. M., Sopiah., 2013. Perilaku Konsumen. Yogyakarta: CV. Andi Offset. Sari, R., dan Soewardikoen, D. W., 2014. Visual Identity and Promotion Media For Integrated Tourism Of North Jakarta. Jurnal Komunikasi Visual Wimba. Volume 06(N0.2/2014). http://www.academia.edu/10214762/visual identity and promotion media for integrated tourism of north jakarta

Soewardikoen, D. W., 2013. Metodologi Penelitian Visual. Bandung: Dinamika Komunika.

Supriyono, R., 2010. Desain Komunikasi Visual. Yogyakarta: CV. Andi Offset.

Wahab, S., 2003. Manajemen Kepariwisataan (Cet.4). Jakarta: PT. Pradnya Paramita.

Wenats, A.G E. dkk., 2012. Integrated Marketing Communication Komunikasi Pemasaran di Indonesia. Jakarta: Gramedia Pustaka Utama.

Wijayanti, T., 2014. Marketing Plan Dalam Bisnis. Jakarta: Elex Media Komputindo. 